\title{
Integrating social collaborative features in learning management system: a case study
}

\begin{abstract}
The growth of Web 2.0 technology and its application has changed our e-learning environment that known as e-learning 2.0. E-learning 2.0 provides many benefits to instructors and learners by enabling them to learn in a social collaborative environment. Many existing platforms have been used by people in higher institutions to support their learning activities such as forum, social media, wiki, and GitHub. However, this application is not designed specifically for learning environment and adopting collaborative learning course is quite challenging. This study was conducted to propose a Learning Management System (LMS) model for software engineering course by integrating social and collaborative features that are suitable with learning practices in higher institutions. Usability testing was conducted to evaluate the proposed social collaborative learning model in terms of usefulness, ease of use and users' satisfaction of the system prototype. Thus, the result shows that the proposed model can be used to support more effective learning practices among instructors and learners in the social collaborative environment.
\end{abstract}

Keyword: E-learning; Social collaborative; Social media; Usability testing 